\section{Rapidly Progressive Infected Coronary Artery Aneurysm}

Kanichi Otowa, MD, PhD; Akio Chikata, MD, PhD; Michiro Maruyama, $\mathrm{MD}, \mathrm{PhD}$;

Kazuo Usuda, MD, PhD

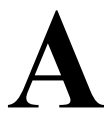

n 81-year-old woman presented to the emergency room with fever, anorexia, and malaise for the past 4 days. Emergency computed tomography (CT) revealed pleural and pericardial effusions (Figure A). Antibiotic therapy was started because methicillin-susceptible Staphylococcus aureus was detected in the pericardial fluid. After admission, contrast-enhanced CT on the 9th day showed an $11 \times 13 \mathrm{~mm}$ coronary aneurysm with hematoma and abscess formation in the proximal right coronary artery (RCA) (Figure B), and she was diagnosed with infected coronary artery aneurysm (ICAA). On the 16th day, CT showed an enlarged pseudoaneurysm of $20 \times 26 \mathrm{~mm}$ (Figure C). On the 30th day, after 4 weeks of antibiotic therapy, coronary angiography showed further enlargement of the pseudoaneurysm to $20 \times 26 \mathrm{~mm}$ (Figure D). On the 35th day, the patient underwent ICAA resection and coronary bypass grafting (Figure E,F; postoperative CT shown in Figure G).

Although ICAA is rare, it is associated with high morbidity and mortality. ${ }^{1}$ By evaluating the patient chronologically by CT, we could reveal expansion of the ICAA.

\section{Disclosures}

The authors declare no conflicts of interest.

\section{Reference}

1. Restrepo CS, Gonzalez TV, Baxi A, Rojas CA. Infected ("mycotic") coronary artery aneurysm: Systematic review. J Cardiovasc Comput Tomogr 2020; 14: e99-e104.

Received July 6, 2021; accepted July 6, 2021; J-STAGE Advance Publication released online August 13, 2021 Time for primary review: 1 day

Department of Cardiology, Toyama Prefectural Central Hospital, Toyama, Japan

Mailing address: Kanichi Otowa, MD, PhD, Department of Cardiology, Toyama Prefectural Central Hospital, 2-2-78 Nishinagae, Toyama 930-8550, Japan. E-mail: otowanomori@gmail.com

All rights are reserved to the Japanese Circulation Society.

For permissions, please e-mail: cj@j-circ.or.jp

ISSN-1346-9843

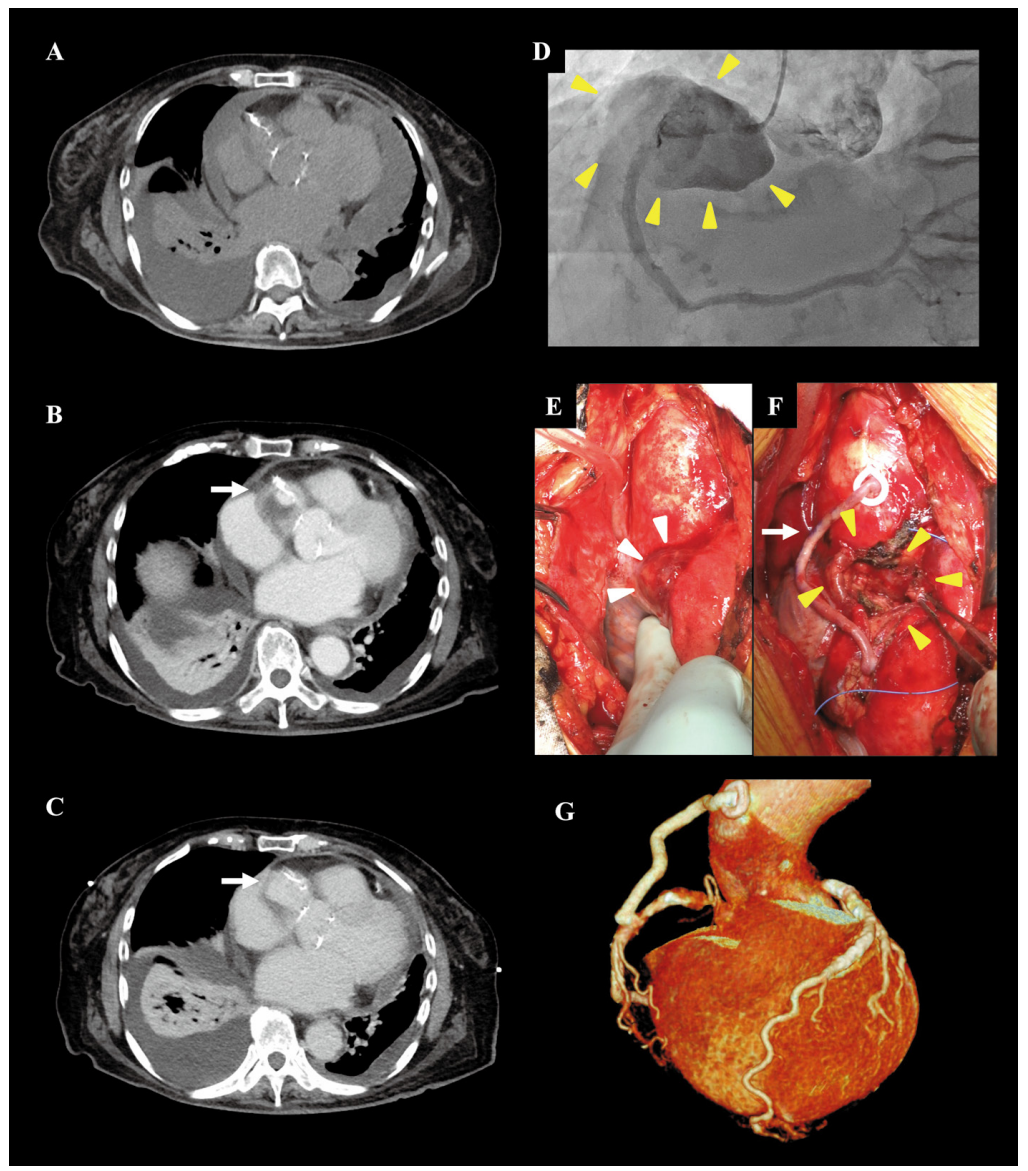

Figure. (A) Plain computed tomography (CT) on admission showing pleural and pericardial effusions. (B) Contrast-enhanced $\mathrm{CT}$, on the 9th day of admission, showing an $11 \times 13 \mathrm{~mm}$ coronary aneurysm with hematoma and abscess formation in the proximal right coronary artery (RCA) (white arrow). (C) Contrast-enhanced CT on the 23rd day of admission, showing a $20 \times 26 \mathrm{~mm}$ coronary aneurysm in the RCA (white arrow). (D) Coronary angiography showing a $24 \times 38 \mathrm{~mm}$ pseudoaneurysm in the RCA on the 30th day of admission (yellow arrowheads). (E) Infected coronary artery aneurysm (white arrowheads). (F) Incised infected coronary artery aneurysm (yellow arrowheads) and saphenous vein graft (white arrow). (G) Contrast-enhanced CT image after coronary bypass grafting. 